\title{
Actions, diagnosis and territorial management of the disaster in the city of Lorca after the earthquake of May 11, 2011
}

\author{
S. G. Veintimilla ${ }^{1}$ \& A. T. Espín ${ }^{2}$ \\ ${ }^{1}$ Department of Civil Engineering, \\ Technical University of Cartagena, Spain \\ ${ }^{2}$ Department of Civil Engineering, \\ Technical University of Cartagena, Spain
}

\begin{abstract}
The Lorca earthquake of May 11, 2011 was the first earthquake with deaths in Spain in the past 40 years. Management of the process and the mechanisms for damage assessment in the city are a topic which, to date, has a scarce tradition in Spanish engineering.

The city of Lorca is located in an environment of certain seismic vulnerability due to the presence of the Alhama fault, so the possibility of another earthquake cannot be ruled out. Therefore, the actions to be undertaken in the urban regeneration must be based on integral tools, such as seismic microzonation, and must affect certain fields of knowledge, such as territorial management and urban planning.

This paper presents new techniques for aftershock management and damage assessment, with the experience acquired in the 2011 earthquake, and analyzes the proposals that are currently being developed in the city of Lorca from the territorial point of view.

Keywords: earthquake management, urban microzonation, aftershock evaluation techniques, seismic territorial management.
\end{abstract}

\section{The Lorca earthquake of May 11, 2011}

The Lorca earthquake of May 11, 2011 had a magnitude of 5.1 on the moment magnitude scale. It was preceded two hours earlier by a premonitory earthquake of 4.5 $\mathrm{M}_{\mathrm{w}}$. The earthquake was also felt in the neighbouring provinces of 
Almeria, Albacete, Granada, Alicante and even in Jaen, Malaga, Ciudad Real and parts of the city of Madrid (Fig. 1). Multiple aftershocks occurred in the hours following the shock of 18:47, with that of the largest magnitude occurring at 22:37 local time, and being 3.9 on the moment magnitude scale.

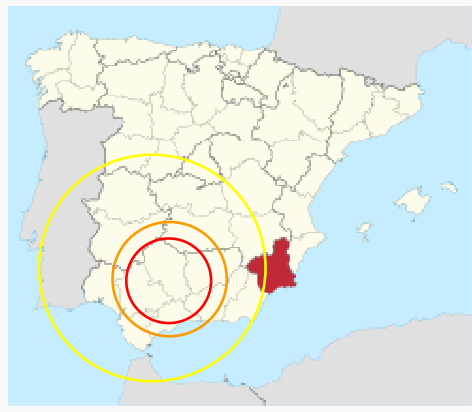

(a)

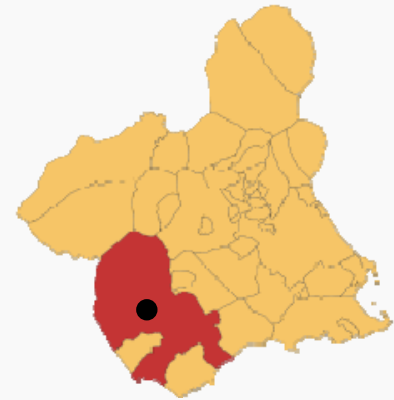

(b)

Figure 1: $\quad$ Location of Lorca in (a) Spain and (b) Murcia.

The Murcia region where Lorca lies is one of the most active seismic zones of Spain. Nevertheless, the Lorca basic acceleration of $0.12 \mathrm{~g}$ in the Spanish standard [1] is not among the most dangerous (Fig. 2).

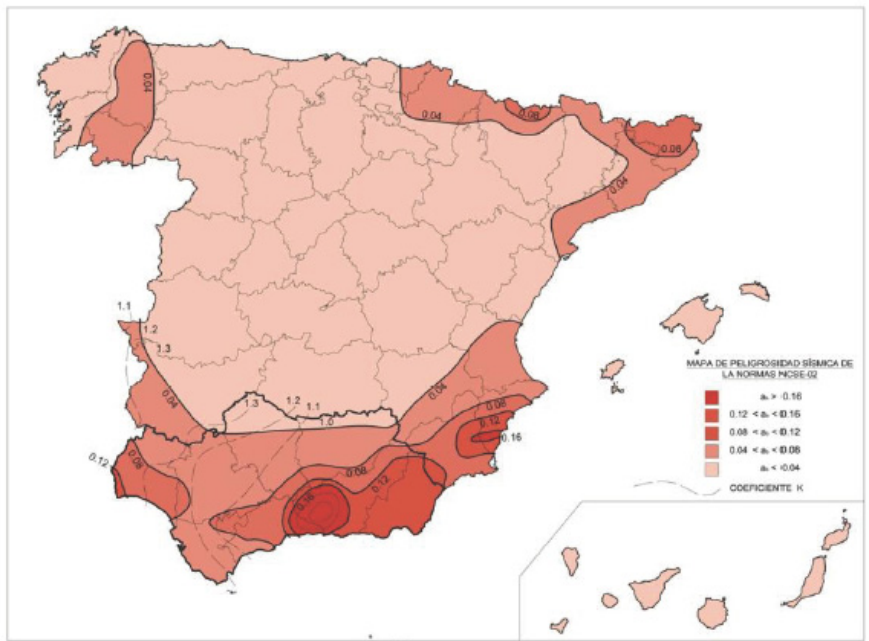

Figure 2: $\quad$ Map of seismic intensities in Spain (source NCSE-02).

The main quake occurred on land approximately $2 \mathrm{~km}$ northeast of the town of Lorca. Its hypocenter was very shallow, at a depth of about 1000 metres. The area is located on the plate boundary between the Eurasian plate and the African plate. However, most of the earthquakes in the region do not often reach 
perceptible magnitudes, and are therefore not usually felt. It has been estimated that the earthquake was a direct result of a strike-slip fault close to another major fault, the Alhama of Murcia one. This fault is a very shallow line, which extends from 40 to $50 \mathrm{~km}$, of which local specialists noted the presence of rupture surfaces in the vicinity [2].

\section{Damage assessment and zoning}

The analysis of this earthquake was particularly interesting from the standpoint of damage. Many public buildings, housing and heritage were affected. Within the zonal distribution of damage, certain areas not particularly close to the epicentre were notable, such as the neighbourhood of La Viña or the old town.

The severity of the shock was largely due to the combination of shallow depth (an earthquake at a depth of one kilometre is very rare in the area) and a moderate magnitude. In Lorca, near the epicentre, large earthworks recorded an intensity of VII on the Mercalli scale, while other nearby areas detected movements of $\mathrm{V}$. The seismic movement as a whole developed the same power as an explosion of $200 \mathrm{t}$ of TNT, about $8.4 \times 10^{11} \mathrm{~J}$ [2].

An estimated $80 \%$ of homes were to some extent damaged, with over 1300 having to be demolished in the following months. However, this distribution of damage was quite heterogeneous and upon analysis did not relate to only seismic parameters. In addition, it should be noted that despite the high number of homes affected, only one building actually collapsed during the earthquake (Fig. 3).

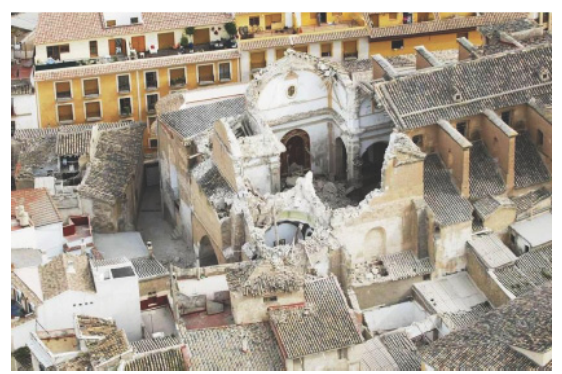

(a)

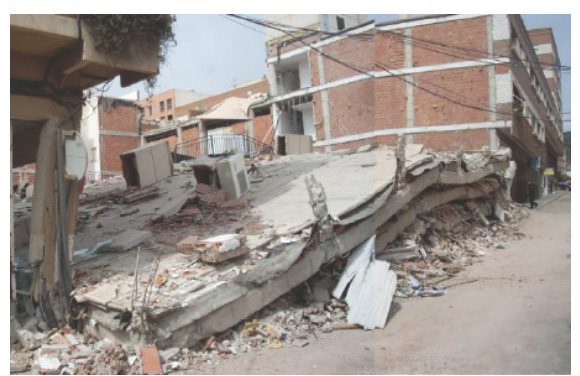

(b)

Figure 3: (a) Church of Santiago. (b) Building collapsed in La Viña.

As compared to the damage to buildings, the infrastructures were barely affected. The viaducts and tunnels of the A-7 road and the urban bridges of the city withstood the earthquake well and only minor damage was reported. In the railway infrastructures, Lorca Sutullena station was the most affected and was demolished, while the Lorca-Águilas line (which itself was rendered unusable by flood damage months later) was barely damaged. Similarly, in water infrastructures such as the dams of Valdeinfierno and Puentes there were no problems, with the only damage being registered in the urban drainage networks. 
With regard to aftershock damage assessment, from the very moment of the earthquake, a large and heterogeneous group of volunteer technicians were responsible for the emergency evaluation of the housing in Lorca, a task in which the authors participated. According to IGN [2] the object of this evaluation corresponds to an initial baseline assessment of safety and habitability of buildings, so the data obtained are approximate. A total of 7839 buildings were analyzed during the first week. These data have been incorporated by the town hall and the Ministry of Public Works and Planning to the municipal mapping database to make available georeferenced damage data for analysis from a territorial perspective.

The buildings were labelled with green, yellow and red labels. The green classification meant safety of use, although the building could have minor damage such as cracks, crevices or small landslides. The yellow rating indicated a damaged building with access available based on the elimination of risk (e.g. the demolition of damaged roofs or parapets). Use of these buildings could also be cautiously granted as long as they had no more than non-decisive structural damage to their overall stability, following a visual inspection. The red label marked a structurally damaged building, with access to the property being prohibited [2].

From the first moment of the evaluation, it could be seen that the distribution of damage was very varied which meant that its explanation required territorial analysis of the urban environment. The asymmetric distribution of parameters such as the urban plot or the nature of the terrain generated an unexpected distribution on many occasions, if a purely traditional seismological analysis was followed.

The town of Lorca (which currently has more than 92,000 inhabitants), sits on a narrowing of the River Guadalentín. It is an area where the river leaves the Cuenca Alta through a pass in the Sierra de la Tercia and which has been used as a place to ford the river since ancient times, which has made it a privileged communication centre for centuries. The activity of the Alhama de Murcia fault has always allowed territorial conditions ideal for urban development, because of the high escarpment that provided the primitive inhabitants of the city with excellent visibility and security. This primitive urban planning has not been without problems. The 1674 earthquake caused extensive damage to the city but marked the beginning of an ambitious program of urban reconstruction, generating a very special baroque district that remains to this day, protected under the planning of a special protection plan [3].

This historic urban district consists mostly of buildings of masonry wall structures with internal elements with a low seismic adaptive capacity. Its construction types are considered highly vulnerable due to their high mass and their low embedment between the wall planes.

Another of the most influential factors in the earthquake registered on a site is called the local effect, which consists in the amplification or attenuation of the ground motion as a function of the geological structure and topography of the urban environment. Spanish seismic law includes a soil amplification parameter that relates directly with a parameter $\mathrm{C}$ which, depending on the characteristics 
of the terrain makes it possible to distinguish four soil types. A simple interpolation of this parameter, based on the high number of existing geotechnical studies in the town of Lorca (Fig. 4) allows us to elaborate a zonification that explains certain results of the earthquake.

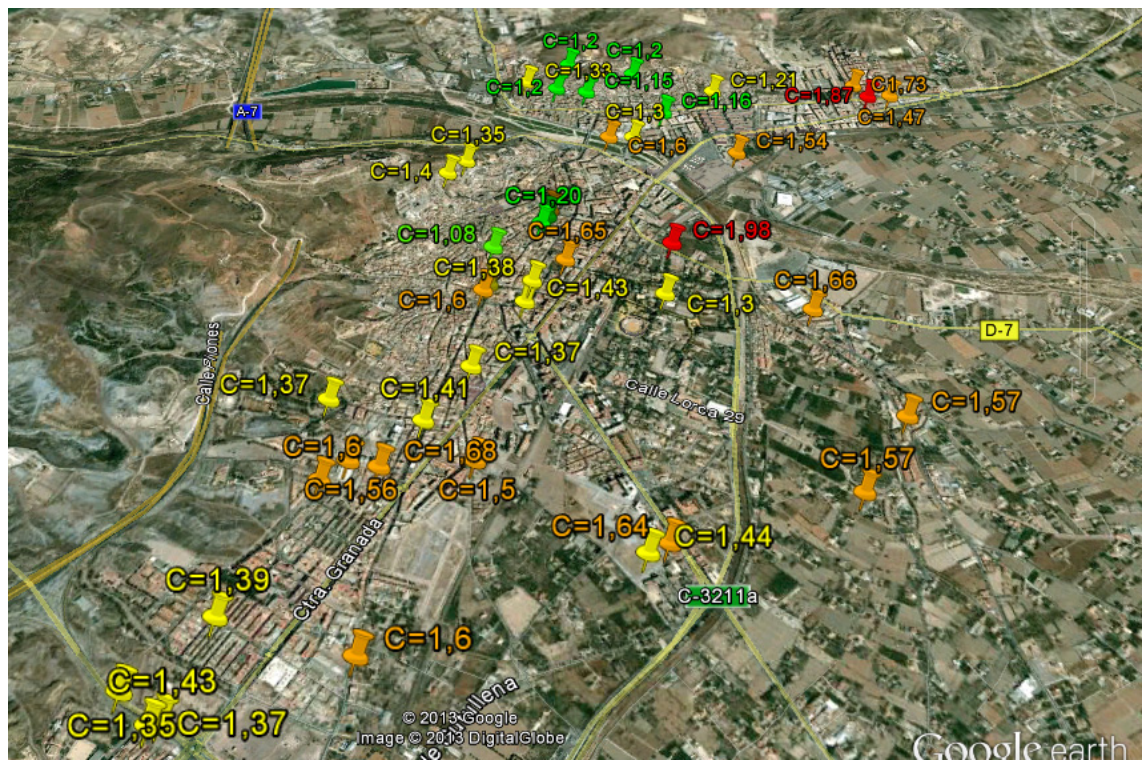

Figure 4: Inventory of terrain amplification factors in Lorca.

From this data, a map overlay of soil characteristics versus damage intensity can be implemented (Fig. 5). An analysis of the incidence of damage out of the total number of buildings for each soil type shows a clear increase in damage to the soil type III, referring to Guadalentín sedimentary deposits. This explains cases such as that of the neighbourhood of San Fernando, where the 232 homes from the nine buildings in the neighbourhood had to be completely demolished because of the serious damage.

Globally, it should be highlighted that damage was analyzed in a total of 5155 buildings in the metropolitan area of Lorca. Of these, 889 (13\% of the total) were initially classified to be yellow or red level. Damage is interesting in some census districts of La Viña neighbourhood, such as the $1013^{\text {th }}$ and $1024^{\text {th }}$ districts, with percentages of damaged buildings of $41 \%$ and $40 \%$ of the total number of buildings of each district. Others, such as the $1004^{\text {th }}$ census district, which is representative of the historic city centre, suffered damage classified in yellow or red in $16 \%$ of its buildings. This case is explained by the parameter classifying the constructive type rather than the soil type.

There are also districts in which the parameter governing the level of damage is basically associated with the topography, such as the neighbourhoods of San Diego and San Cristobal. In some cases, such as the $1027^{\text {th }}$ district, leading to the Avenue of the Armed Forces damage was to over $40 \%$ of all the buildings. 


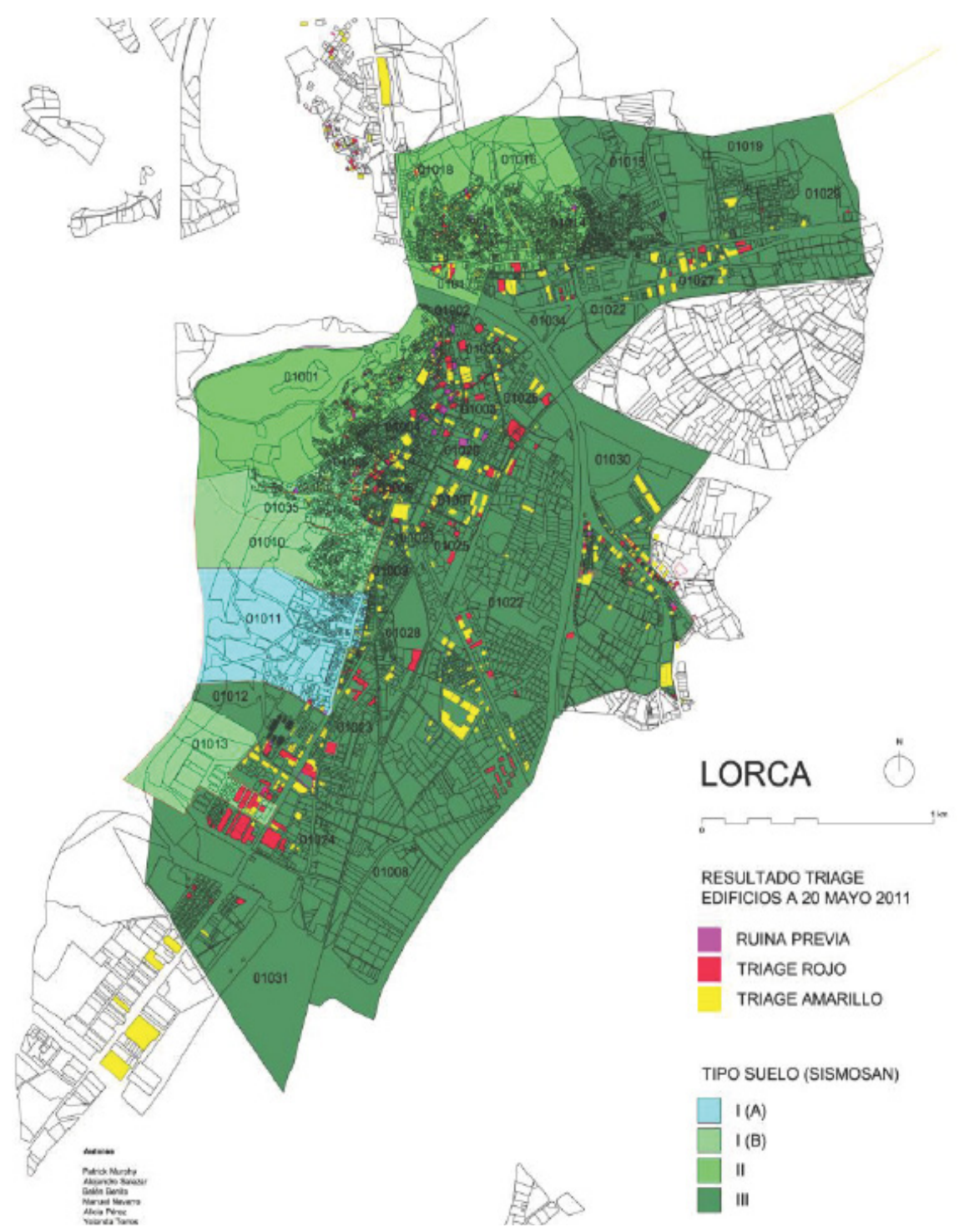

Figure 5: Overlapping of damage over soil types (source: Sismozon).

\section{New evaluation techniques for information and aftershock management}

An important aspect to consider after an earthquake is that damage evaluation provides homogeneous information of the affected area. There are, however, usually distorting variables (capacity of the evaluators, subjectivity, information management, etc.) as we can see from acquired experience (Table 1). 
Table 1: Damaged building classification categories.

\begin{tabular}{|c|c|c|c|}
\hline & Turkey (1999) & Colombia (2009) & Chile (2010) \\
\hline $\begin{array}{c}\text { GREEN } \\
\text { (safe, usable or } \\
\text { habitable) }\end{array}$ & $\begin{array}{l}\text { Little or no } \\
\text { structural damage. } \\
\text { Temporary } \\
\text { occupation } \\
\text { allowed. }\end{array}$ & $\begin{array}{l}\text { Low risk for global } \\
\text { stability, geotechnical } \\
\text { problems, structural } \\
\text { damage and / or non- } \\
\text { structural damage. }\end{array}$ & $\begin{array}{l}\text { No damage or very } \\
\text { limited on the } \\
\text { whole. } \\
\text { No restrictions on } \\
\text { use. }\end{array}$ \\
\hline $\begin{array}{l}\text { YELLOW } \\
\text { (caution, } \\
\text { restricted entry } \\
\text { or temporary } \\
\text { disablement, } \\
\text { dubious safety) }\end{array}$ & $\begin{array}{l}\text { Damage to } \\
\text { structural and / or } \\
\text { non-structural } \\
\text { elements. } \\
\text { Temporary } \\
\text { occupation not } \\
\text { allowed, except for } \\
\text { emergencies. }\end{array}$ & $\begin{array}{c}\text { Low risk, after } \\
\text { measurements, global } \\
\text { stability, geotechnical } \\
\text { problems, structural } \\
\text { damage and / or non- } \\
\text { structural damage. }\end{array}$ & $\begin{array}{l}\text { Damage, structural } \\
\text { or non-structural } \\
\text { sufficient for } \\
\text { controlled risk to } \\
\text { people. } \\
\text { Partial closure and } \\
\text { limited entry. }\end{array}$ \\
\hline $\begin{array}{c}\text { ORANGE } \\
\text { (unhabitable) }\end{array}$ & Not specified. & $\begin{array}{l}\text { High risk for global } \\
\text { stability, geotechnical } \\
\text { problems, structural } \\
\text { damage or non- } \\
\text { structural damage. }\end{array}$ & Not specified. \\
\hline $\begin{array}{c}\text { RED } \\
\text { (risk, unsafe or } \\
\text { disablement) }\end{array}$ & $\begin{array}{l}\text { Significant risk of } \\
\text { collapse with } \\
\text { aftershocks. } \\
\text { Entry not allowed. } \\
\text { Measures to } \\
\text { prevent sudden } \\
\text { collapse. }\end{array}$ & $\begin{array}{l}\text { High risk for at least } \\
\text { two (or very high for } \\
\text { at least one) of the } \\
\text { following reasons: } \\
\text { global stability, } \\
\text { geotechnical } \\
\text { problems, structural } \\
\text { damage, non- } \\
\text { structural damage. }\end{array}$ & $\begin{array}{l}\text { Elevated damage } \\
\text { involving high risk } \\
\text { of injury to } \\
\text { persons. } \\
\text { The building } \\
\text { should be closed. }\end{array}$ \\
\hline
\end{tabular}

In the case of the Lorca earthquake no lives were lost due to the structural collapse of a building or infrastructure. Most of the material damage was associated with wrong urban configurations or little care in the construction details, with the most common structural pathologies being phenomena such as soft plant, short pillars or poor design in reinforced concrete.

Based on the experience gained in this earthquake, the UPCT has proposed a quick aftershock assessment form to ensure safety [4]. The building located in the Aprendices Square had an unexpected collapse during its demolition due to the damage on the ground floor and first floor (Fig. 6). It had, according to its evaluator, only serious damage in facades and the fall of part of the breastplate housing, causing the financial ruin of the building. 


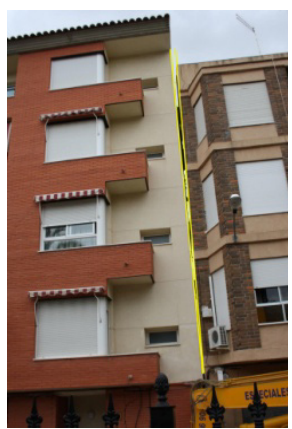

(a)

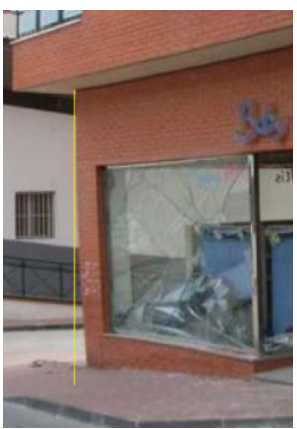

(b)

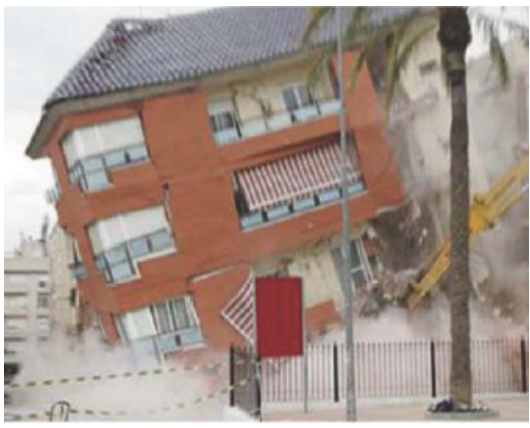

(c)

Figure 6: Building in danger of collapse. Evidence of crashes in (a) joint between buildings and (b) corner pillar. (c) Collapse.

According to the proposed form, this building would be a level 4 (very high) estimated risk of loss of global stability and level 2 (moderate) non-structural risk. Therefore, it would be classified as a potential collapse (black colour), as it has at least one level 4 classification (Fig. 7).

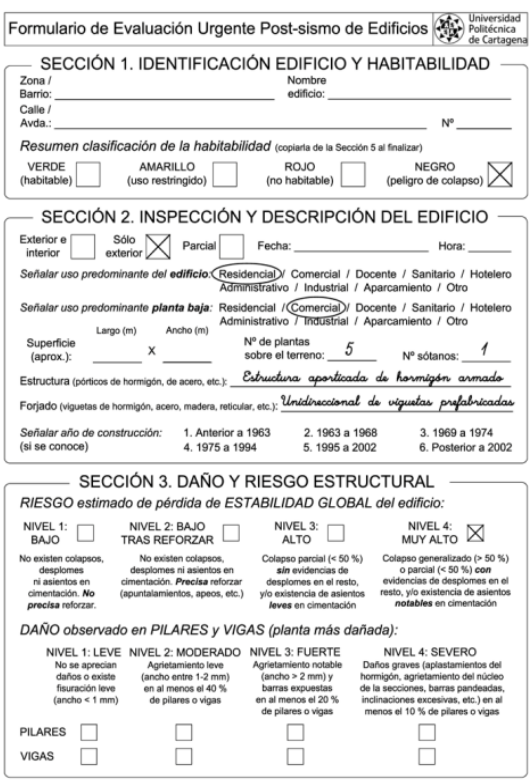

(a)

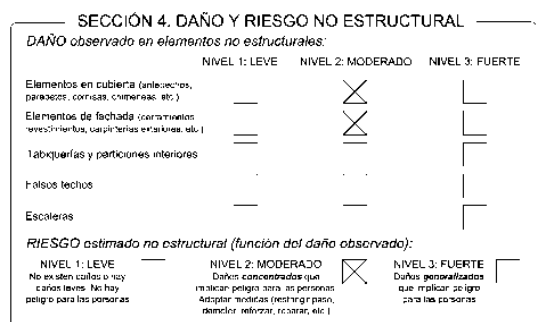

SECCION 5. CLASIFICACION DE LA HABITABILIDAD

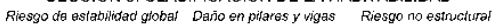

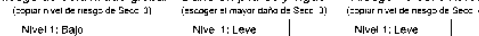

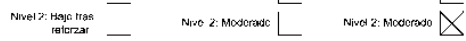

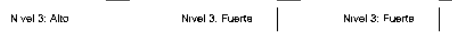
Nivo 4 Muy jlu $\chi \quad$ Nivel 4: Severo $\square$

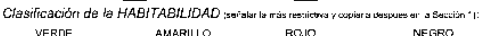

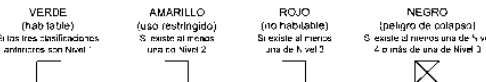

SECCIÓN 6. DATOS DE CONTACTO Y COMENTARIOS

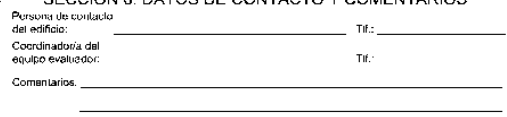
(b)

Figure 7: Building with danger of collapse. Completion of the proposed form. (a) Front. (b) Back. (Source: Tomás and Díaz [4].) 


\section{The territorial management perspective in the analysis of the seismic vulnerability of cities}

After the 2011earthquake the Region of Murcia has launched certain planning measures in order to eliminate seismic vulnerabilities of its territory. In order to be prepared against a possible new earthquake it has accelerated the SISMIMUR plan update [5] by the Emergency Department. This plan specifies the seismic hazard, estimates vulnerability, the seismic risk in terms of damage and produces a catalogue of risk factors for buildings of particular importance that are located in areas where the intensity can be equal to or greater than VII for a return period of 475 years in the Region of Murcia.

In the same direction, another interesting measure to qualify the level of the available staff for the building design has been to start developing seismic strategy guides from the Ministry of Works and Planning of Murcia. These technical documents establish clear rules of seismic design for the reconstruction of buildings and provide rapid aftershock assessment protocols with standardized forms [6].

At a local level, a strategic action to prepare the city of Lorca for a possible new earthquake lies in adequate planning. Lorca is a city under reconstruction and in continuous urban growth (Fig. 8).

In this sense, the project commissioned by the Ministry of Works and Planning of Murcia to the Technical University of Cartagena of microzoning Lorca is very interesting. This is a standard procedure in cities with a seismic tradition such as Tokyo, Bogota or Santiago de Chile, but is a pioneering project for this size in Spain. The above-mentioned microzoning is now being addressed from a holistic and multidisciplinary perspective that is able to combine fields of knowledge such as seismic, geological, geotechnical or structural engineering. It will also cover innovative areas such as territorial planning and land use, after detecting in the 2011 earthquake phenomena associated with topography, urban growth in undue environments risk or the urban configuration of buildings in an earthquake.

After the earthquake of May 11, there were some voices that postulated the possibility of modifying the existing seismic code (NCSE-02 for buildings) due to the acceleration of $0.369 \mathrm{~g}$ achieved in an environment where the norm envisages just $0.12 \mathrm{~g}$, with the possibility of extending this to $0.196 \mathrm{~g}$ under certain assumptions. The presence, however, of most damage associated with inadequate designs without any seismic quality and the lack of regard for any of the recommendations of the standard itself in effect denies the need.

The problem therefore lies rather in the need to adapt the local factor of each environment rather than to conduct an overall review and update of the state regulations after the occurrence of specific events. In many cases, the local effect is dominant on the effects of the source and wave propagation, and thus, its inclusion in the estimation of the expected ground motion is of prime importance.

Quantifying the local effect is very complex because it involves many aspects. In studies at regional scale such as SISMIMUR, more or less simple 
geological classifications tend to be employed, encompassing different soil types in the region of study. For each class an average amplification factor is adopted, which is applied to the estimated motion in hard rock or soil, thus the resulting movement includes the local effect [5].

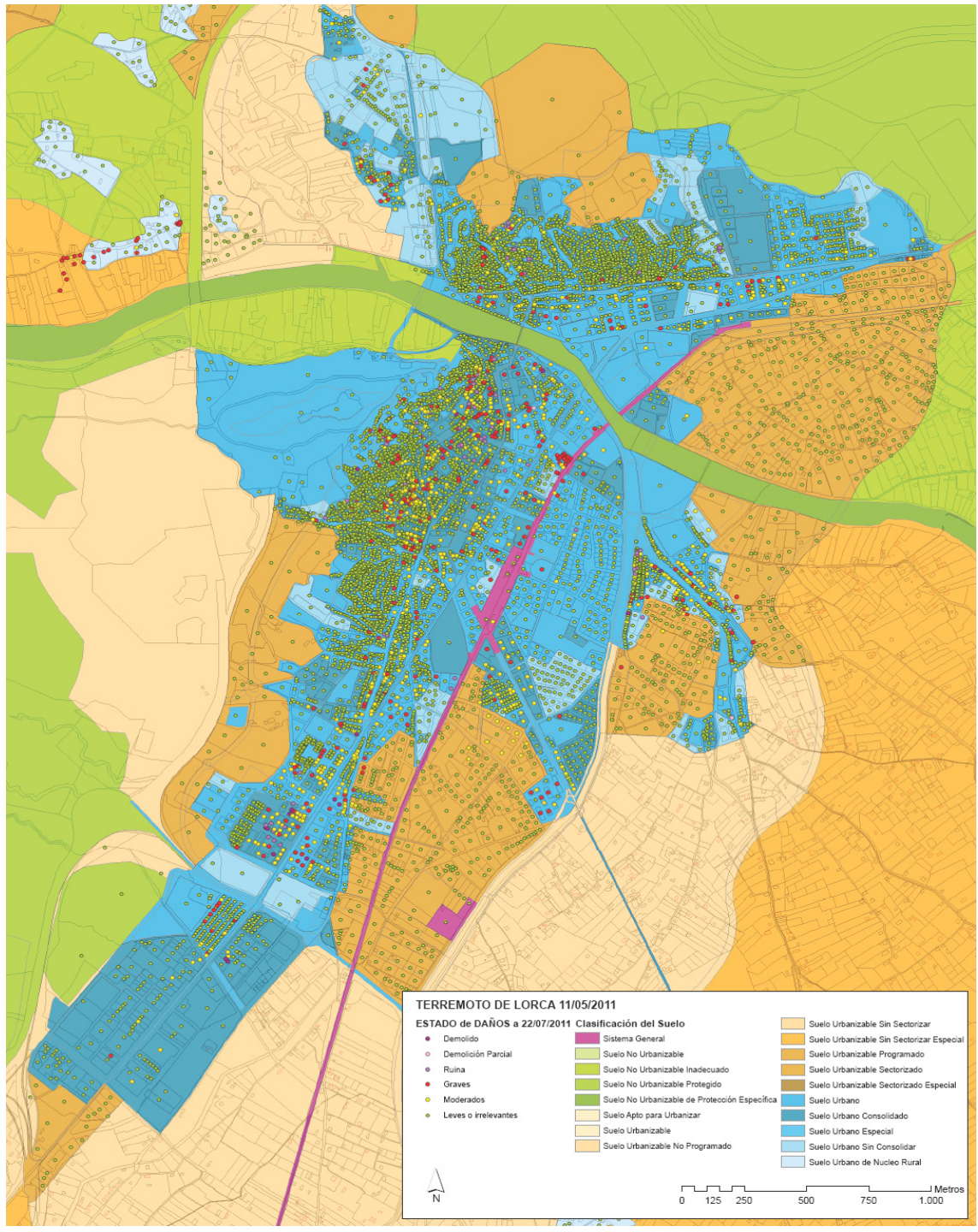

Figure 8: Distribution of damage in urban planning schedule.

In this field, it is important to consider the necessary adaptation of many buildings now to be rebuilt with CTE legislation approved in 2007. This will alter the original configuration of almost all these buildings. That presents a 
unique opportunity to review the entire General Plan, the principal technical tool in the Spanish legal system at municipal level. A new more technological general plan with urban growth and development, taking into account the territorial results of microzoning performed would reduce as far as possible the seismic vulnerabilities of the city with the proven risk of Lorca and it would be a very useful and innovative tool.

\section{Conclusions and future performances}

The experience provided by the Lorca earthquake of May 11, 2011 brings us the following conclusions:

1. It is necessary to implement a planning and seismic strategy with fast action protocols. These protocols should incorporate damage assessment forms, which are rigorous yet simple and adaptable to a massive intervention by technicians and volunteers.

2. It is very important to integrate the local seismic factor. It is not necessary to cause general changes in seismic regulations based on specific events, but to update tools that empower at regional and local level to prevent seismic vulnerabilities in the various municipalities.

3. The large number of buildings that will require having their configuration modified during the rebuilding because of the need to adapt to current building regulations recommends a complete overhaul of the General Municipal Plan in Lorca. Technifying urban planning, adapting building typologies to particular seismic problems based on tools such as microzoning or SISMIMUR in cities with high risk of major seismic events or vulnerabilities like Lorca, is recommended as a future policy.

\section{References}

[1] Seismic Standards Standing Committee, Seismic construction standard: general and building (NCSE-02). Ministry of Development: Madrid, 2002.

[2] Geological and Mining Institute of Spain, Preliminary geological report Lorca earthquake of May 11, 2011, 5.1 Mw. Ministry of Science and Innovation: Madrid, 2011.

[3] Council of Lorca, General Urban Plan of Lorca. Lorca, Spain, 2007.

[4] Tomás, A. \& Díaz, E., Proposal of a form for post-earthquake rapid evaluation of buildings. Internal report, Department of Civil Engineering, Technical University of Cartagena (UPCT): Cartagena, Spain, 2013.

[5] General Directorate of Civil Protection, Civil protection special plan to the seismic risk in the Region of Murcia (SISMIMUR). Department of the Presidency of the Region of Murcia: Murcia, Spain, 2006.

[6] Department of Public Works and Planning of the Region of Murcia, Guidelines for the definition of an antiseismic strategy. FHECOR Knowledge: Murcia, Spain, 2012. 